\title{
HEALTH BELIEF MODEL FOR THE ANALYSIS OF FACTORS AFFECTING HYPERTENSION PREVENTIVE BEHAVIOR AMONG ADOLESCENTS IN SURAKARTA
}

\author{
Rumeyda Chitra Puspita1), Didik Tamtomo²), Dono Indarto3) \\ ${ }^{1)}$ Masters Program in Public Health, Sebelas Maret University \\ 2)Department of Anatomy, Faculty of Medicine, Sebelas Maret University \\ 3)Department of Physiology, Faculty of Medicine, Sebelas Maret University
}

\begin{abstract}
Background: Hypertension is an important public health issue in developed and developing countries. The incidence of hypertension continues to rise to a serious level. Raising awareness of the seriousness of hypertension among peer groups may be an important factor for preventive health behavior. This study aimed to examine the used of health belief model for the analysis of factors affecting hypertension preventive behavior among adolescents.

Subjects and Method: This study was an observational analytic study with cross sectional design. It was conducted at 5 Vocational High Schools (SMK) in Surakarta from April to May, 2017. A sample of 200 class X and XI SMK students aged 15-17 years was selected for this study by stratified random sampling. The dependent variable was hypertension preventive behavior. The independent variables were perceived susceptibility, perceived seriousness, perceived benefit, perceived barriers, cues to action, and self efficacy, with perceived threat as a mediating variable. The data were collected by a set of pre-tested questionnaire. Path analysis was employed for data analysis using SPSS AMOS 22.

Results: Perceived threat $(b=0.24, S E=0.07, p=0.002)$, perceived benefit $(b=0.24, \mathrm{SE}=0.10, \mathrm{p}=0.021)$, self efficacy $(\mathrm{b}=0.40, \mathrm{SE}=0.23, \mathrm{p}=0.084)$, and cues to action $(b=0.45, \mathrm{SE}=0.15, \mathrm{p}=0.003)$ showed direct positive effects on hypertension preventive behavior. Perceived barrier $(b=-0.26, \mathrm{SE}=$ $0.10, p=0.015)$ showed direct negative effect on hypertension preventive behavior. Perceived susceptibility $(b=0.27, \mathrm{SE}=0.09, \mathrm{p}=0.005)$, perceived seriousness $(b=0.29, \mathrm{SE}=0.09, \mathrm{p}<0.001)$, and cues to action $(b=0.34, \mathrm{SE}=$ $0.13, p=0.008)$ showed indirect positive effects on hypertension preventive behavior.

Conclusion: Hypertension preventive behavior is positively and directly affected by perceived threat, perceived benefit, self, and cues to action. The preventive behavior is negatively and directly affected by perceived barrier. Perceived susceptibility, perceived seriousness, and cues to action indirectly and positively affect on hypertension preventive behavior.
\end{abstract}

Keywords: health belief model, hypertension, preventive behavior, adolescents

Correspondence: Rumeyda Chitra Puspita. Masters Program in Public Health, Sebelas Maret University, Jl. Ir. Sutami 36 A, Surakarta 57126, Central Java, Indonesia. Email: rumeydacp@gmail.com.

Mobile: +6287736044472. 